\title{
Using echocardiography and chest ultrasound for guidance of management of difficult-to-wean COPD patients
}

\begin{abstract}
Background: The Pathophysiology of mechanical ventilation weaning failure in COPD patients is often complex and Multifactorial. Cardiac dysfunction, Lung dysfunction and diaphragm dysfunction might contribute either alone or in combination to that condition. This work aims to assess the utility of integrated basic echocardiography and chest ultrasound in management of difficult -to - wean COPD patients.

Methods: This prospectively cross sectional study was conducted upon 31 difficultto-wean mechanically ventilated COPD patients in Respiratory ICUs of Ain Shams University Hospitals Patients; who were clinically judged by the treating physician to be ready for weaning; underwent a spontaneous breath trial (SBT) using T-piece. Combined echocardiography study and thoracic ultrasound were performed at the end of successful trial or with the beginning of signs of SBT failure.
\end{abstract}

Results: There was a statistically significant relation between the presence ischemic heart diseases, elevated right ventricle systolic pressure (RVSP), low ejection fraction\% (EF\%), evidence of left ventricular diastolic dysfunction, development of B lines, decreased diaphragmatic thickness index and SBT outcome.

In patients with failed SBT elevated RVSP was the most frequent finding (69\%), followed by left ventricular diastolic dysfunction $(62 \%)$, low $\mathrm{EF} \%(38 \%)$, B lines $(62 \%)$, and diaphragmatic thickness index $<20 \%(25 \%)$. Combined B lines and diastolic dysfunction at end of SBT was the most frequent finding associated with failed SBT. The lung ultrasound findings were interpreted as indicative of interstitial edema and SBT failure was attributed to increased left ventricular pressure and a diuretic therapy with or without vasodilators was recommended. The presence of consolidation, pleural effusion, and decreased diaphragmatic thickness index were poor predictors of SBT trial failure in our COPD patients

Conclusions: Concomitant ultrasonography assessment of cardiac, lung, and diaphragm functions is a helpful tool in monitoring of SBT and in determining the most likely cause of failure. This may help guidance of weaning in such cases.

Keywords: Weaning failure, spontaneous breathing trial (SBT), combined chest and basic cardiac ultrasound
Volume II Issue 4 - 2018

Marwa Sayed Daif,' Magdy M Khalil,' Hala M Salem,' Ayman Morttada Abd El Moteleb, ${ }^{2}$ Hossam-El Din MAbd-Elhamid'

'Departments of Pulmonary Medicine, Faculty of Medicine,Ain Shams University, Egypt

2Department of Cardiology Medicine, Faculty of Medicine, Ain Shams University, Egypt

Correspondence: Ayman Morttada Abd El Moteleb, Department of Cardiology Medicine, Faculty of Medicine, Ain Shams University, Cairo, Egypt, Email aymanmor@hotmail.com

Received: July 15, 2018 | Published: August 07, 2018

\section{Introduction}

Weaning of mechanical ventilation; in most patients; can be done; as soon as; the underlying reason for acute respiratory failure has been resolved. $20 \%$ to $30 \%$ of patients are considered difficult to wean from mechanical ventilation Weaning failure is defined as the failure to pass a spontaneous-breathing trial or the need for re-intubation within 48 hours following extubation. ${ }^{1}$ COPD (chronic obstructive pulmonary disease) is frequently associated with cardiac comorbidity and diaphragmatic dysfunction. Transthoracic echocardiography (TTE) was found useful to detect spontaneous breathing trial (SBT)induced changes in central hemodynamics. ${ }^{2}$ Elevated left ventricular end diastolic pressure during weaning may induce pulmonary and bronchial wall edema which increases the work of breathing. ${ }^{3}$ Another factor is myocardial ischemia which may occur in response to increased respiratory workload, resulting spontaneous breathing trial failure. ${ }^{4}$ When performed by an experienced operator prior to SBT, TTE may help in identifying patients at high risk of cardiac- related weaning failure. Thoracic Ultrasound is also an important tool in revealing pulmonary pathologies that might delay weaning of mechanically ventilated COPD patients e.g. consolidation, collapse, pleural effusion, pneumothorax, diaphragmatic dysfunction. Previous studies focused on isolated organ contribution to weaning failure ignoring interaction between organs and multifactorial etiology of outcome of this rather complex issue.

The aim of this work was to study the utility of integrated ultrasonographic information in defining the most probable cause(s) of weaning failure in the individual COPD patient.

\section{Patients and methods}

This study was prospectively conducted on 31 difficult-to-wean mechanically ventilated COPD patients in Respiratory ICUs of Ain Shams University Hospitals. Diagnosis of COPD was based upon: clinical, radiological and arterial blood gas (ABGs) analysis. Prior spirometric results were included if available. ${ }^{5}$ The patient was 
considered difficult-to-wean: if he/she required more than 7 days of weaning after the first spontaneous breathing trial (SBT) provided by the treating physician.

Inclusion criteria: Patients fulfilling criteria of readiness for weaning were subjected to SBT: lung disease is stable/ resolving, $\mathrm{FiO}_{2}<0.5$, and PEEP $<5 \mathrm{cmH}_{2} \mathrm{O}$, haemodynamic stability (low vasopressors doses are accepted), and able to initiate spontaneous breaths. ${ }^{6}$

Exclusion criteria: Patients who refuse to participate in the study or poor quality of ultrasonographic imaging.

Spontaneous breath trial: Spontaneous breathing trial was done through a T-piece over a maximum period of 120 minutes. Failure of SBT was considered if any of the following occurs during the trial: respiratory rate $\mathrm{RR}>38 \mathrm{bpm}$ or $<6 \mathrm{bpm}$ for 5 minutes, $\mathrm{SpO}_{2}<92 \%$ under $\mathrm{FiO}_{2} \geq 0.5$, heart rate: $\mathrm{HR}>140$ or $25 \%$ above baseline or $\mathrm{HR}<60$, systolic blood pressure $\geq 40 \mathrm{~mm} \mathrm{Hg}$ above baseline, worsening agitation, anxiety or discomfort despite reassurance, or rapid shallow breathing index (RSBI): $>105 \mathrm{~min} / \mathrm{L},{ }^{6}$ Combined thoracic and cardiac ultrasound was performed at the end of the trial or with the beginning of signs of SBT failure. Patients with successful SBT were followed over next 48 hours for the successful extubation or reintubation.

Ultrasound (US) examination methodology: Mindray M7 portable ultrasound machine with three standard probes was used for examination of the patients.

Transthoracic echocardiography (TTE): Basic cardiac ultrasound was done using micro echocardiography probe ( 3 to $12 \mathrm{MHz}$ ). The following areas were assessed: apical, subcostal, and parasternal (short and long axes). The following findings were assessed: ventricular size and wall, ventricular function, pericardial effusion, assessment of the valves, inferior vena cava diameter and collapsibility, and any other abnormalities.
Thoracic ultrasound: Patients were assessed in semi recumbent/ supine position. Curvilinear probe ( 3 to $12 \mathrm{MHz}$ ) was used to visualize the lungs and pleura. The following US findings were assessed: lung sliding, alveolar consolidation and/or collapse, pleural effusion, A lines, B lines and diaphragmatic thickness index (thickness at end inspiration- thickness at end expiration/thickness at end expiration).

Lower limb venous duplex was done if there was suspicion of presence of DVT.

Statistical analysis: Data were collected, checked and analyzed using Epi-Info version 6 and SPSS for Windows version 14.0 (SPSS, Chicago, IL, USA). Data were summarized using mean, standard deviation (SD), Analysis of variance Fisher exact test, Chi-Square test and Student's t-test. The threshold of significance is fixed at 5\% level (P-value), $\mathrm{P}$ value of $>0.05$ indicates non significant results, $\mathrm{P}$ value $<$ 0.05: Significant ( $\mathrm{S}$ ) and $\mathrm{P}<0.01$ : Highly significant (HS).

\section{Results}

This prospective study was conducted upon 31 difficult-to-wean COPD patients (30 males and 1 female); with mean age $69 \pm 18$ years and BMI $28 \pm 7 \mathrm{~kg} / \mathrm{m}^{2}$. Duration of mechanical ventilation was $38.7 \pm 36.4$ days in failure group and $9.6 \pm 3.5$ days in success group. Twenty three patients $(74.1 \%)$ had endotracheal tube and 8 patients $(25.8 \%)$ had tracheostomy tube during SBT. Successful trials were $18(58 \%)$ and failed trials were $13(41.9 \%)$. There was no relation between SBT outcome and history of previous MV but duration of current MV was significantly longer in SBT failure group.

Tables (1-6) summarize the ultrasonographic findings and their relation to SBT outcome there was a highly significant relation between presence of ischemic heart disease and SBT outcome but there was no statistically significant relation between either of diabetes mellitus, hypertension and renal impairment to SBT outcome (Table 1).

Table I Relation of co-morbidities of studied patients to their SBT outcome

\begin{tabular}{|c|c|c|c|c|c|c|c|}
\hline & & \multicolumn{4}{|c|}{ SBT } & \multirow{2}{*}{\multicolumn{2}{|c|}{ Test of significance }} \\
\hline & & \multicolumn{2}{|c|}{ Failure } & \multicolumn{2}{|c|}{ Success } & & \\
\hline & & $\mathbf{N}$ & $\%$ & $\mathbf{N}$ & $\%$ & $P$ value & Sig. \\
\hline \multirow{2}{*}{ Hypertension } & Negative & 2 & $15.4 \%$ & 6 & $33.3 \%$ & \multirow{2}{*}{$0.412(F)$} & \multirow{2}{*}{ NS } \\
\hline & Positive & 11 & $84.6 \%$ & 12 & $66.7 \%$ & & \\
\hline \multirow{2}{*}{ Diabetes mellitus } & Negative & 9 & $69.2 \%$ & 8 & $44.4 \%$ & \multirow{2}{*}{$0.17 I(C)$} & \multirow{2}{*}{ NS } \\
\hline & Positive & 4 & $30.8 \%$ & 10 & $55.6 \%$ & & \\
\hline \multirow{2}{*}{ Ischemic heart disease } & Negative & 5 & $38.5 \%$ & 18 & $100.0 \%$ & \multirow{2}{*}{$0.00 I(F)$} & \multirow{2}{*}{ HS } \\
\hline & Positive & 8 & $61.5 \%$ & 0 & $0.0 \%$ & & \\
\hline \multirow{2}{*}{ Renal function } & Normal & 12 & $92.3 \%$ & 12 & $66.7 \%$ & \multirow{2}{*}{$0.191(\mathrm{~F})$} & \multirow{2}{*}{ NS } \\
\hline & High & I & $7.7 \%$ & 6 & $33.3 \%$ & & \\
\hline
\end{tabular}

F: Fisher exact test, C: Chi square test, SBT: spontaneous breathing trial

Table 2 Chest ultrasound findings in studied patients at the end of SBT in relation to their SBT outcome

\begin{tabular}{|c|c|c|c|c|c|c|c|}
\hline & & \multicolumn{4}{|c|}{ SBT } & \multirow{2}{*}{\multicolumn{2}{|c|}{$\begin{array}{l}\text { Test of } \\
\text { significance }\end{array}$}} \\
\hline & & \multicolumn{2}{|c|}{ Failure } & \multicolumn{2}{|c|}{ Success } & & \\
\hline & & $\mathbf{N}$ & $\%$ & $\mathbf{N}$ & $\%$ & $P$ value & Sig. \\
\hline \multirow{2}{*}{ A lines } & Negative & 6 & $46.2 \%$ & 7 & $38.9 \%$ & \multirow{2}{*}{$0.686(\mathrm{C})$} & \multirow{2}{*}{ NS } \\
\hline & Positive & 7 & $53.8 \%$ & II & $61.1 \%$ & & \\
\hline
\end{tabular}


Table Continued

\begin{tabular}{|c|c|c|c|c|c|c|c|}
\hline & & \multicolumn{4}{|l|}{ SBT } & \multirow{2}{*}{\multicolumn{2}{|c|}{$\begin{array}{l}\text { Test of } \\
\text { significance }\end{array}$}} \\
\hline & & \multicolumn{2}{|l|}{ Failure } & \multicolumn{2}{|c|}{ Success } & & \\
\hline & & $\mathbf{N}$ & $\%$ & $\mathbf{N}$ & $\%$ & $P$ value & Sig. \\
\hline \multirow{2}{*}{ Consolidation } & Negative & 10 & $76.9 \%$ & II & $61.1 \%$ & \multirow{2}{*}{$0.452(\mathrm{~F})$} & \multirow{2}{*}{ NS } \\
\hline & Positive & 3 & $23.1 \%$ & 7 & $38.9 \%$ & & \\
\hline \multirow{5}{*}{ Pleural effusion } & Negative & 7 & $53.8 \%$ & 6 & $33.3 \%$ & \multirow{2}{*}{$0.253(\mathrm{C})$} & \multirow{2}{*}{ NS } \\
\hline & Positive & 6 & $46.2 \%$ & 12 & $66.7 \%$ & & \\
\hline & & \multicolumn{2}{|l|}{ SBT } & & & \multirow{2}{*}{\multicolumn{2}{|c|}{$\begin{array}{l}\text { Test of } \\
\text { significance }\end{array}$}} \\
\hline & & failure & & success & & & \\
\hline & & Mean & SD & Mean & SD & $P$ value & Sig. \\
\hline \multicolumn{2}{|c|}{ Diaphragmatic thickness Index } & $40.91 \%$ & $24.30 \%$ & $59.64 \%$ & $11.62 \%$ & $0.037(\mathrm{~T})$ & $\mathrm{S}$ \\
\hline
\end{tabular}

T: $t$ test, F: Fisher exact test, C: Chi square test, SBT: spontaneous breathing trial

Table 3 Echocardiography findings in studied patients at the end of SBT in relation to their SBT outcome

\begin{tabular}{|c|c|c|c|c|c|c|c|}
\hline & & \multicolumn{4}{|l|}{ SBT } & \multirow{2}{*}{\multicolumn{2}{|c|}{$\begin{array}{l}\text { Test of } \\
\text { significance }\end{array}$}} \\
\hline & & \multicolumn{2}{|c|}{ Failure } & \multicolumn{2}{|c|}{ Success } & & \\
\hline & & $\mathbf{N}$ & $\%$ & $\mathbf{N}$ & $\%$ & $P$ value & Sig. \\
\hline \multirow{2}{*}{ LT side size } & Normal & 12 & $92.3 \%$ & II & $61.1 \%$ & \multirow{2}{*}{$0.095(\mathrm{~F})$} & \multirow{2}{*}{ NS } \\
\hline & Dilated & I & $7.7 \%$ & 7 & $38.9 \%$ & & \\
\hline \multirow{2}{*}{ Diastolic dysfunction } & Negative & 5 & $38.5 \%$ & 18 & $100 \%$ & \multirow{2}{*}{$0.000(\mathrm{~F})$} & \multirow{2}{*}{$\mathrm{S}$} \\
\hline & Positive & 8 & $61.5 \%$ & 0 & $0 \%$ & & \\
\hline \multirow{2}{*}{ RT side size } & Normal & 12 & $92.3 \%$ & 12 & $66.7 \%$ & \multirow{2}{*}{$0.191(\mathrm{~F})$} & \multirow{2}{*}{ NS } \\
\hline & Dilated & 1 & $7.7 \%$ & 6 & $33.3 \%$ & & \\
\hline \multirow{2}{*}{ Regional motion abnormality } & Negative & 12 & $92.3 \%$ & 15 & $83.3 \%$ & \multirow{2}{*}{$0.191(\mathrm{~F})$} & \multirow{2}{*}{ NS } \\
\hline & Positive & 1 & $7.7 \%$ & 3 & $16.7 \%$ & & \\
\hline \multirow{5}{*}{ Pericardial effusion } & Negative & 10 & $76.9 \%$ & 10 & $55.6 \%$ & \multirow{2}{*}{$0.235(F)$} & \multirow{2}{*}{ NS } \\
\hline & Positive & 3 & $23 \%$ & 8 & $44.4 \%$ & & \\
\hline & & \multirow{2}{*}{\multicolumn{2}{|c|}{$\begin{array}{l}\text { SBT } \\
\text { Failure }\end{array}$}} & & & \multirow{2}{*}{\multicolumn{2}{|c|}{$\begin{array}{l}\text { Test of } \\
\text { significance }\end{array}$}} \\
\hline & & & & Succes & & & \\
\hline & & Mean & SD & Mean & SD & $P$ value & Sig. \\
\hline \multicolumn{2}{|l|}{ TAPSE } & 1.8 & 0.9 & 2.4 & 0.8 & $0.072(\mathrm{~T})$ & NS \\
\hline
\end{tabular}

$\mathrm{T}: \mathrm{t}$ test, F: Fisher exact test, SBT: spontaneous breathing trial

Table 4 Distribution of studied patients at the end of SBT regarding grade of EF\% and RVSP in relation to their SBT outcome

\begin{tabular}{|c|c|c|c|c|c|c|}
\hline \multirow[t]{2}{*}{ EF\% } & & \multicolumn{2}{|c|}{ Test of Significance } \\
\hline & $\mathbf{N}$ & $\%$ & $\mathbf{N}$ & $\%$ & p value & sig. \\
\hline $65-77$ & I & $7.7 \%$ & 13 & $72.2 \%$ & & \\
\hline $55-64$ & 7 & $53.8 \%$ & 3 & $16.7 \%$ & $0.00 I(F)$ & $S$ \\
\hline $40-54$ & 5 & $38.5 \%$ & 2 & $11.1 \%$ & & \\
\hline \multirow[t]{2}{*}{ RVSP(mmHg) } & \multicolumn{2}{|c|}{$\begin{array}{l}\text { SBT } \\
\text { Failure }\end{array}$} & \multicolumn{2}{|c|}{ Success } & \multicolumn{2}{|c|}{ Test of Significance } \\
\hline & $\mathbf{N}$ & $\%$ & $\mathbf{N}$ & $\%$ & p value & sig. \\
\hline $15-24$ & I & $7.7 \%$ & 12 & $66.7 \%$ & \multirow{4}{*}{$<0.00 \mathrm{I}(\mathrm{F})$} & \multirow{4}{*}{$S$} \\
\hline $25-40$ & 3 & $23.1 \%$ & 5 & $27.8 \%$ & & \\
\hline $4 \mid-55$ & 4 & $30.8 \%$ & I & $5.6 \%$ & & \\
\hline$>55$ & 5 & $38.5 \%$ & 0 & $0.0 \%$ & & \\
\hline
\end{tabular}

F: Fisher exact test, SBT: spontaneous breathing trial, EF: ejection fraction, RVSP: right ventricular systolic pressure

Citation: Daif MS, Khalil MM, Salem HM, et al. Using echocardiography and chest ultrasound for guidance of management of difficult-to-wean COPD patients. J Cardiol Curr Res. 2018; I (4): I78-I84. DOI: 10.15406/jccr.2018.II.00394 
Table 5 Distribution of studied patients regarding inferior vena cava (IVC) collapsibility index in relation to their SBT outcome

\begin{tabular}{lllllll}
\hline & SBT & & & & \multicolumn{2}{l}{ Test of } \\
& Failure & & success & & \multicolumn{2}{c}{ Significance } \\
& Mean & SD & Mean & SD & p value & sig. \\
\hline $\begin{array}{l}\text { IVC } \\
\begin{array}{l}\text { collapsibility } \\
\text { Index }\end{array}\end{array}$ & $26.60 \%$ & $22.11 \%$ & $39.73 \%$ & $23.66 \%$ & $0.176(\mathrm{~T})$ & NS \\
\hline
\end{tabular}

T: $t$ test, SBT: spontaneous breathing trial

Table 6 Lower limb venous ultrasonography findings in studied patients in relation to their SBT outcome

\begin{tabular}{|c|c|c|c|c|c|c|c|}
\hline & & \multicolumn{4}{|c|}{ SBT } & \multirow{2}{*}{\multicolumn{2}{|c|}{$\begin{array}{l}\text { Test of } \\
\text { Significance }\end{array}$}} \\
\hline & & \multicolumn{2}{|c|}{ Failure } & \multicolumn{2}{|c|}{ Success } & & \\
\hline & & $\mathbf{N}$ & $\%$ & $\mathbf{N}$ & $\%$ & $\begin{array}{l}P \\
\text { value }\end{array}$ & sig. \\
\hline \multirow{2}{*}{$\begin{array}{l}\text { Lower limb } \\
\text { venous ultra- } \\
\text { sonography }\end{array}$} & Normal & 13 & $100.0 \%$ & 17 & $94.4 \%$ & \multirow[b]{2}{*}{$I(F)$} & \multirow[b]{2}{*}{ NS } \\
\hline & Abnormal & 0 & $0.0 \%$ & I & $5.6 \%$ & & \\
\hline
\end{tabular}

There was a statistically significant relation between presence of B lines and diaphragmatic thickness index to SBT outcome but there was no statistically significant relation between presence of A lines, consolidation and pleural effusion to SBT outcome.

There was a statistically significant relation between LV diastolic dysfunction and SBT outcome but there was no statistically significant relation between either of right ventricular size, left ventricular size, regional motion abnormality and tricuspid annular plane systolic excursion (TAPSE) and SBT outcome. There was a statistically significant relation between level of RVSP and EF\% and SBT outcome. There was no statistically significant relation between inferior vena cava (IVC) collapsibility index and SBT outcome Scanning lower limbs for deep venous thrombosis was positive in one patient of the successful SBT group.

\section{Impact of chest and cardiac US on the management}

In patients with B profile and left ventricular diastolic dysfunction, interstitial oedema was assumed and a combination of diuretic and vasodilator was prescribed. Patients with ischemic heart disease with low EF\% received anti- ischemic measures. In the absence of B profile another cause for SBT failure was looked for e.g. consolidation (C pattern) which was assumed to represent a new or unresolved infection. A pattern was considered as an indication of uncontrolled COPD. Patients with diaphragmatic dysfunction were recommended for a multidisciplinary approach including respiratory therapy.

\section{Discussion}

The pathophysiology of weaning failure is complex and often multifactorial. Accordingly, determining the reason and subsequently developing a treatment strategy require a dedicated clinician with indepth knowledge of the pathophysiology of weaning failure. ${ }^{7}$ Several items should be evaluated in a difficult-to wean patient: airway and lung dysfunction, cardiac dysfunction, diaphragm dysfunction, brain dysfunction, and endocrine dysfunction. ${ }^{8}$

Preexisting cardiovascular and respiratory disorders increases the risk of extubation failure. ${ }^{9}$ Myocardial ischemia may occur in response to increased respiratory workload, resulting in the failure of a spontaneous breathing trial. ${ }^{4}$ Cardiac function is demonstrated to be significantly associated with mortality, the clinical implication is that echocardiography can be routinely obtained for patients with COPD after admission to the ICU to better inform the clinical outcomes, so, interventions including fluid restriction, using of inotropes and diuretics may confer a beneficial effect when guided by echocardiography. ${ }^{10,11,12,13}$

Thoracic Ultrasound is an important tool to reveal lung pathologies that might delay weaning of mechanically ventilated COPD patients e.g. collapse, consolidation, pleural effusion and pneumothorax. ${ }^{2} \mathrm{We}$ hypothesized that combined bedside echocardiography and thoracic ultrasonographic assessment could more accurately detect the causes of respiratory failure in COPD patients undergoing weaning trial. The present study was prospectively conducted upon 31 difficult-to-wean mechanically ventilated COPD patients in Respiratory ICUs of Ain Shams University Hospitals.

\section{From the present study the following results were obtained}

There was no statistically significant relation between SBT outcome and patients' age $(\mathrm{p}=0.453)$, or gender $(\mathrm{p}=1)$. The study of Ghoneim et al., ${ }^{14}$ which was carried out at the Respiratory Intensive Care Unit of Chest Department, Zagazig University Hospitals, showed that there was no significant effect of the age or gender $(p=0.68)$ on the weaning outcome. The severity of the underlying disease and the general condition of the patients were much more determinant factors of the weaning outcome than the age or gender. Smoking status had no role in affecting weaning outcome; however, it can affect severity of the disease. ${ }^{14}$

There was statistically significant relation with duration of present mechanical ventilation $(\mathrm{P}=0.014)$. The duration of MV before SBT trial could indirectly reflect the severity of the initial injury, the progressive weakness of respiratory muscle, and the occurrence of complications, each of them may contribute to difficult weaning. There was no statistically significant relation between history of previous mechanical ventilation and SBT outcome $(\mathrm{P}=0.237)$. The results of Ghoneim et al., ${ }^{14}$ however showed that weaning failure was more evident in patients who were previously mechanically ventilated $(\mathrm{p}=0.032)$.

The transfer of a patient from positive pressure ventilation to spontaneous ventilation is associated with increased venous return and negative intra-thoracic pressure causing increased left ventricular after load and increased myocardial oxygen consumption. So, latent or unrecognized myocardial dysfunction can become manifested at the imitation of the weaning attempts. Also, the emotional stress due to abrupt disconnection from MV can result in adrenergic response with subsequent tachycardia and increase cardiac demand. In the present study, there was statistically highly significant relation between presence of ischemic heart diseases and SBT outcome $(\mathrm{P}=0,000)$, which matches with the results of Ghoneim et al. ${ }^{14}$

In the present study there was statistically significant relation between left ventricular ejection fraction $(\mathrm{EF} \%)(\mathrm{P}=0.001)$, left ventricular diastolic dysfunction $(\mathrm{P}=0.000)$, right ventricle systolic pressure (RVSP) $(\mathrm{P}<0.001)$ and SBT outcome. ${ }^{15}$ This agrees with the results of Porhomayon et al., ${ }^{16}$ that showed that ischemic heart disease and systolic or diastolic dysfunction contributes to increase in cardiac load and weaning failure. Extra demand on cardiac working 
load imposed by SBT may become apparent when transferring patient from positive to spontaneous ventilation.

Furthermore, this results were in agreement with the results of Vincent et al., ${ }^{17}$ which was conducted in the ICU of two University hospitals, and showed that both the increase of E/A, (ratio of maximal mitral $\mathrm{E}$ wave and $\mathrm{A}$ wave velocities $)(\mathrm{P}=0.003)$ and shortened DTE (deceleration time of mitral $\mathrm{E}$ wave $)(\mathrm{P}=0.00001)$ during the
SBT suggest that altered LV diastolic properties may potentially contribute to the rise in LV filling pressure. Ankush et al., ${ }^{18}$ reported that echocardiography can help in both prognosis and follow up of patients on MV. In the current study, elevated RVSP was the most frequent ultrasonographic finding (69\%) in SBT failure group, Figure 1-3 followed by left ventricular diastolic dysfunction (61.5\%), low $\mathrm{EF} \%(38 \%) .{ }^{19}$

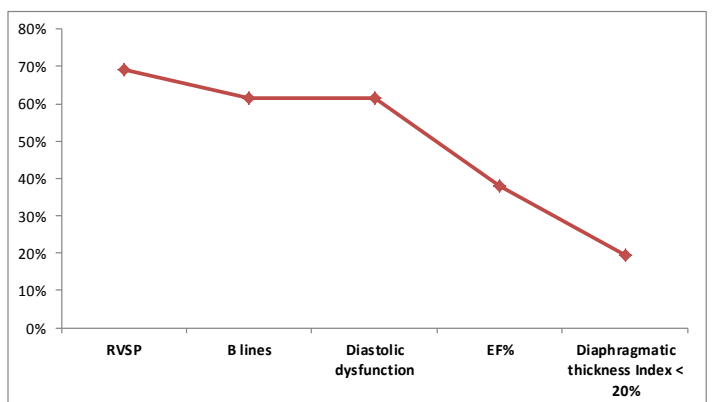

Figure I This figure shows that elevated RVSP (right ventricular systolic pressure) was the most frequent ultrasonographic finding (69\%) in SBT failure group, followed by left ventricular diastolic dysfunction (61.5\%), low EF\% (38\%), the B lines (61.5\%), and diaphragmatic thickness index $<20 \%(19.3 \%)$.
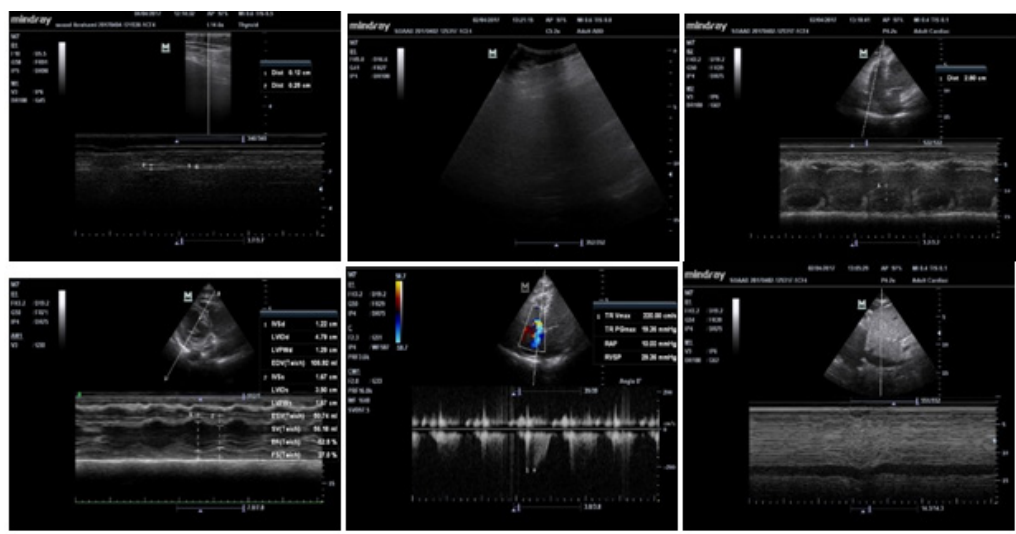

Figure $2 \mathrm{~A} 70$ - year old COPD female patient, ex smoker ( 0.5 pack / day for 40 years), with diabetes mellitus and hypertension, and history of previous mechanical ventilation one year ago. Duration of present mechanical ventilation 10 days, failed weaning twice, at third trial of SBT: chest ultrasound was normal, diaphragmatic thickness index $=52 \%$, EF $53 \%$, grade I diastolic dysfunction, RVSP $40 \mathrm{mmHg}$ with mild TR, normal size of right side of heart, TAPSE = $2.8 \mathrm{~cm}$, IVC collapsibility index $=50 \%$, normal lower limb venous ultrasonography. The SBT was successful, and the patient was weaned from MV.
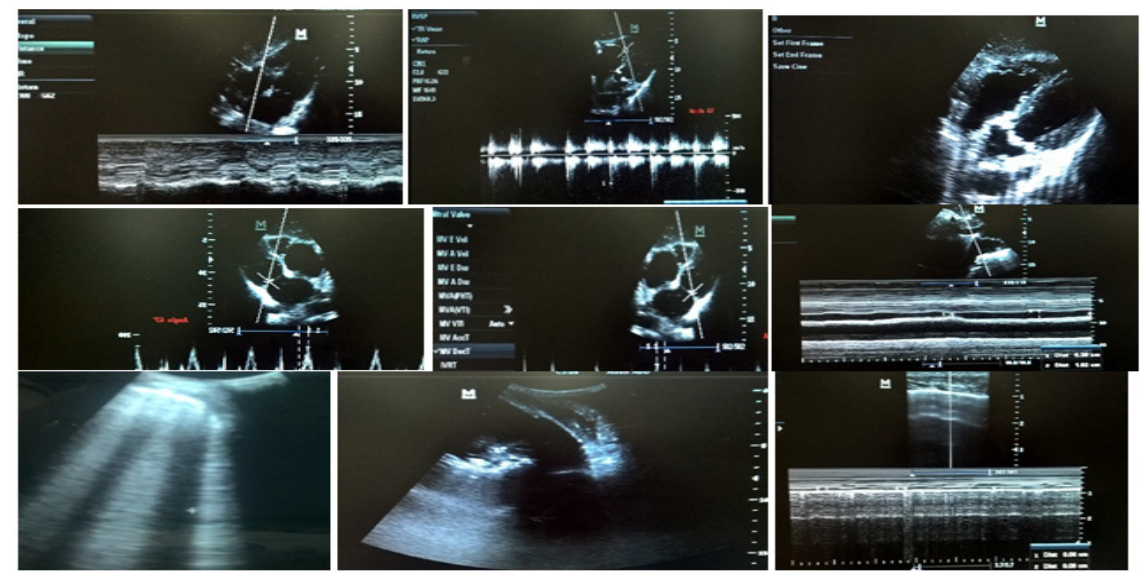

Figure 3 A 72 -year old COPD male patient, ex smoker (2 packs / day for 20 years), with diabetes mellitus, hypertension and ischemic heart disease, and history of previous mechanical ventilation once 2 years ago. Duration of present mechanical ventilation was 25 days. The patient failed weaning for 10 times. The current SBT was done while on tracheostomy tube. Chest ultrasound showed right lower lobe consolidation and mild pleural effusion, $B$ lines was evident over of anterior lung areas, diaphragmatic thickness index $=33 \%$, EF $48 \%$, grade 3 diastolic dysfunction, RVSP 65 mmHg with moderate TR and MR, dilated right side of heart, TAPSE $=1.1 \mathrm{~cm}$, IVC collapsibility index $=60 \%$, and normal lower limb venous ultrasonography. The SBT failed. Recommendations based on US findings included intensifying/ changing antimicrobial regimen, and intensifying /modifying anti-failure and anti-ischemic measures. 
In the present study, there was no statistically significant relation between inferior vena cava (IVC) collapsality index and SBT outcome $(\mathrm{P}=0.176)$, which matches with the results of a study by Airapetian et al., ${ }^{20}$ performed in two ICUs at Amiens University Medical Center (Amiens, France), where echocardiography and doppler ultrasound were used to record the stroke volume (SV), cardiac output (CO) and IVC collapsibility index (cIVC) ((maximum diameter (IVC max)minimum diameter (IVC min))/ IVC max) at baseline, after a passive leg-raising maneuver (PLR) and after $500 \mathrm{ml}$ of saline infusion, which showed that neither the IVC diameter nor IVC variability $(\mathrm{P}=0.4)$ accurately predict fluid responsiveness in spontaneously breathing patients hospitalized in the ICU.

In our study as regards the chest ultrasound, there was statistically significant relation between $\mathrm{B}$ lines and SBT outcome $(\mathrm{P}=0.000)$, which was in agreement with the results of Antonio et al., ${ }^{18}$ who observed the behavior of lung ultrasound findings during spontaneous breathing trial on fifty-seven subjects eligible for ventilation weaning, and showed that in the SBT failure group, there was a slightly statistical trend of increasing B-predominance during the T-piece trial $(p=0.07)$ as spontaneous inspiration led to increase the venous return and possible cardiac decomposition or pulmonary edema.

In our study, there was no statistically significant relation between A lines $(p=0.686)$ and SBT outcome. Lines represent aeration of the lungs and absence of significant lung pathology that might affect the course of SBT. On the contrary, loss of lung aeration during the spontaneous breathing trial in non-dependent lung zones was demonstrated in subjects who failed to wean, Antonio et al., ${ }^{18}$ Same results were reported by Silva et al. ${ }^{19}$ who observed the ultrasound data from 136 patients who were extubated after passing a trial of pressure support ventilation. The authors concluded that loss of lung aeration (absent A lines) could predict postextubation distress.

In our study, there was no statistically significant relation between consolidation $(\mathrm{p}=0.452)$ and SBT outcome which matches the results of Silva et al., ${ }^{19}$ which showed that the detection of lung consolidation (C profile) was weakly associated with the rate of postextubation distress.

In present study, there was statistically significant relation between diaphragmatic thickness index and SBT outcome $(\mathrm{P}=0.037)$, which matches with the results of the study of El Morsy et al., ${ }^{21}$ which was carried out on 67 mechanically ventilated patients who were admitted to Critical Care Medicine Department in Alexandria main university hospital, and showed that progressive diaphragmatic atrophy, detected by B-mode ultrasonography, is associated with high sensitivity, specificity, positive and negative predictive values to determine weaning failure in addition to association with prolonged duration of mechanical ventilation as well as prolonged ICU stay, for patients on different modes of mechanical ventilation. Silva et al., ${ }^{19}$ stated that thoracic ultrasound assessment permits an accurate monitoring of some pivotal physiologic processes that are implicated in the postextubation distress, including diaphragm dysfunction.

In the subgroup of SBT failure in the present study, the RVSP was the most frequent ultrasongraphic finding $(69 \%)$, followed by left ventricular diastolic dysfunction (61.5\%), low EF\%, B lines (61.5\%), and diaphragmatic thickness index $<20 \%(19.3 \%)$. When the findings of combined ultrasound are integrated, a cause of SBT failure could be purported. In patients with B profile and left ventricular diastolic dysfunction, interstitial oedema was assumed and a combination of diuretic and vasodilator was prescribed. In the absence of B profile another cause was looked for e.g. consolidation (C pattern) which was interpreted as new or unresolved infection. A- pattern was considered as an indication of uncontrolled COPD. Diaphragmatic dysfunction was considered as a contributing factor when the diaphragmatic thickness index was $<20 \%$, though its impact on SBT failure was questionable.

Silva et al., ${ }^{19}$ observed the ultrasound data, measured immediately after the start and at the end of a successful trial of pressure support ventilation, from 136 patients (non COPD, in a mixed medical ICU). The authors developed an integrated thoracic ultrasound predictive model, and reported that lung interstitial water (B profile) appeared to be the most relevant predictive factors of post extubation distress and that the noninvasive estimation of the left ventricular telediastolic pressure appeared to have a significant predictive role compared with echocardiographic parameters used to assess left ventricular systolic function. Finally, it was highlighted that the ultrasound assessment of diaphragm had a poor impact over the final prediction of post extubation distress. The author of the latter study concluded that the use of combined thoracic ultrasound appeared to be highly accurate in identifying the causes of post extubation distress.

In our study, there was no statistically significant relation between diabetes mellitus, hypertension and renal impairment as comorbidity and SBT outcome which matches with the results of Doorduin et al., ${ }^{15}$ who stated that the role of endocrine dysfunction in weaning failure has never been systematically evaluated, but is most likely of limited importance.

\section{Conclusion}

Concomitant ultrasonographic assessment of cardiac, lung, and diaphragm functions is a helpful tool in monitoring outcome of SBT in difficult-to-wean COPD patient and in identifying the most likely cause of failure.

\section{Recommendations}

Development of new diagnostic models to integrate clinical and combined ultrasonographic (chest, diaphragm, cardiac) findings during SBT for accurate prediction of weaning outcome.

\section{Limitations of the study}

Limited number of cases and the lack of initial ultrasonographic findings at the start of SBT.

\section{Acknowledgments}

None.

\section{Conflict of interest}

The author declares that there is no conflict of interest.

\section{References}

1. Boles JM, Bion J, Connors A, et al. Weaning from mechanical ventilation. Eur Respir J. 2007;29:1033-1056.

2. Caille V, Amiel JB, Charron C, et al. Echocardiography: a help in the weaning process. Crit Care. 2010;14(3):R120.

3. Chien JY, Lin MS, Huang YC, et al. Changes in B-type natriuretic peptide improve weaning outcome predicted by spontaneous breathing trial. Crit Care Med. 2008;36(5):1421-6. 
4. Lamia B, Maizel J, Ochagavia A, et al. Echocardiographic diagnosis of pulmonary artery occlusion pressure elevation during weaning from mechanical ventilation. Crit Care Med. 2009;37(5):1696-1701.

5. GOLD. Global strategy for the diagnosis, management, and prevention of chronic obstructive pulmonary disease; chap 1. 2017.

6. Macintyre NR. Evidence-based assessments in the ventilator discontinuation process. Respiratory Care. 2012;57(10):1611-168.

7. Carley S, Driscoll P. Trauma education. 2001;48:4756.

8. Heunks LM, van der Hoeven JG. Clinical review: The ABC of weaning failure-a structured approach. Critical Care. 2010;14(6):245.

9. Kulkarni AP, Agarwal V. Extubation failure in intensive care unit: predictors and management. Indian J Crit Care Med. 2016;12(1):1-9.

10. Soummer A, Perbet S, Brisson H, et al. Lung Ultrasound Study Group: Ultrasound assessment of lung aeration loss during a successful weaning trial predicts postextubation distress. Crit Care Med. 2012;40(7):2064 2072.

11. Kim WY, Suh HJ, Hong SB, et al. Diaphragm dysfunction assessed by ultrasonography: Influence on weaning from mechanical ventilation. Crit Care Med. 2011;39(12):2627-2630.

12. Zhang $\mathrm{Z}$, Chen $\mathrm{L}$, Chen $\mathrm{K}$, et al. The prognostic value of cardiac dysfunction assessed by bedside echocardiography in critically ill patients with COPD requiring mechanical ventilation: a study protocol. BMJ Open. 2014;4(9):e005359.

13. Ambrosino N, Gabbrielli L. The Difficult-to-wean Patient. Expert Rev
Respir Med. 2010;4(5):685-692.

14. Ghoneim AH, El-Komy HM, Gad DM, et al. Assessment of weaning failure in chronic obstructive pulmonary disease patients under mechanical ventilation in Zagazig University Hospitals. Egyptian Journal of Chest Diseases and Tuberculosis. 2017;66(1):65-74.

15. Doorduin J, van der Hoeven JG, Heunks LM. The differential diagnosis for failure to wean from mechanical ventilation. Current Opinion in Anesthesiology. 2016;29(2):150-157.

16. Porhomayon J, Papadakos P, Nader ND. Failed weaning from mechanical ventilation and cardiac dysfunction. Critical Care Research and Practice. $2012 ; 173-177$

17. Vincent C, Amiel JB, Charron C, et al. Echocardiography: a help in the weaning process. Crit Care. 2010;14(3):R120.

18. Antonio AC, Teixeira C, Castro PS, et al. Behavior of lung ultrasound findings during spontaneous breathing trial. Revista Brasileira de Terapia Intensiva. 2017;29(3):279-286.

19. Silva S, Aissa DA, Cocquet P, et al. Combined thoracic ultrasound assessment during a successful weaning trial predicts postextubation distress. Anesthesiology. 2017;127(4):666-674.

20. Airapetian N, Julien M, Alyamani O, et al. Does inferior vena cava respiratory variability predict fluid responsiveness in spontaneously breathing patients?. Critical Care. 2015;19:400.

21. El Morsy AA, Ibrahim MR and Sakr MMA. Serial ultrasonographic evaluation of diaphragm thickness during mechanical ventilation in ICU patients. Bio life. 2015;3(4):922-936. 